\title{
Knowledge and Attitude of Abortion among women of Reproductive age group attending Manipal Teaching Hospital, Nepal
}

${ }^{*}$ Laxmi Adhikari ${ }^{1}$, Isha Karmacharya ${ }^{1}$, Netra Bahadur Karki ${ }^{2}$, Maheshor Kaphle ${ }^{3}$, Sandhya Shrestha ${ }^{4}$

Authors Info:

${ }^{1}$ Lecturer, CiST College, Baneshwor, Kathmandu ${ }^{2}$ Institute of Medicine, Maharajgunj, Kathmandu ${ }^{3}$ Associate Professor, CiST College, Baneshwor ${ }^{4}$ Associate Professor, Manipal College of Medical Sciences, Pokhara

${ }^{*}$ Corresponding Author:

Laxmi Adhikari

Lecturer, CiST College,

Baneshwor, Kathmandu,

Nepal

Email:

luxmiadhikari67@gmail.com

\section{Disclaimer:}

Conflict of Interest: None Source of Support: None Copyright (c) 2019 by author(s), licensed under the Creative Commons Attribution International License 4.0. License 4.0.

\section{ABSTRACT:}

Background: Abortion was legalized in Nepal in September 2002 by the amendment to the "MulukiAin". Legal, moral and ethical issues surrounding abortion make research on all aspects of abortion difficult to undertake. Collecting good information on the reasons for abortion may be especially difficult, because it requires asking women to articulate the often complex and sensitive process that led to the decision.

Objective: The objective of this study is to assess knowledge and attitude regarding abortion among women of Reproductive age group (15-45 years).

Methods: This study was a Cross-sectional descriptive and conducted in Manipal Teaching Hospital (MTH), Pokhara, Nepal. The tools were demographic proforma, knowledge questionnaire and attitude scale on abortion. Data was collected by asking questions regarding abortion. Total sample was 100 and sampling technique was purposive. The data was analyzed using Excel 2007, SPSS for Windows Version 16.0

Results: Majority (83\%) of the respondents were of age group 15-30years, most (70\%) of them were married and $82 \%$ of them were Hindu. Majority (52\%) had nuclear family and $90 \%$ of the participants were literate. Ninety five percentages of the respondents had heard regarding Abortion and majority of them (55\%) got information from mass media. Most (58\%) of the women were having average knowledge regarding Abortion, and remaining $4 \%$ were having poor knowledge. It was also found that majority (90\%) of the women had good attitude and no one was having unfavorable attitude. There was a significant association between knowledge and the level of education. And also, there was a positive correlation between knowledge and attitude of abortion.

Conclusion: Though majority of the women had the good attitude regarding abortion, still few women (4\%) attending MTH didn't have the good knowledge. Therefore woman should be educated about various aspects of abortion which may help to decrease the number of maternal morbidity and mortality due to unsafe abortion.

Keywords: Abortion, Attitude, knowledge, Reproductive Age

\begin{tabular}{|c|}
\hline Article Info \\
\hline Received: October 3, 2019 \\
\hline Accepted: November 27, 2019 \\
\hline Published Online: December 12, 2019 \\
\hline How to cite this article in Vancouver Style? \\
\hline $\begin{array}{l}\text { Adhikari L, Karmacharya I, Karki NB,Kaphle M, Shrestha } \\
\text { S. Knowledge and Attitude on Abortion among women } \\
\text { of Reproductive age group attending Manipal Teaching } \\
\text { Hospital, Nepal. Europasian J Med Sci. 2019;1(1):16-20. } \\
\text { https://doi.org/10.46405/ejms.v1i1.9 }\end{array}$ \\
\hline
\end{tabular}

Access this article online
Publisher Note:
The Europasian Journal of Medical Quick Response (QR) Code
Sciences (EJMS) is an official
Journal of Nirvana Psychosocial
Care Center \& Ressearch Institute
www.nirvanapscc.com. The Journal
as well as publisher remain neutral
with regards to any jurisdictional
claims in any published articles,
its contents and the institutional
affiliations of the authors.




\section{INTRODUCTION}

Abortion is the expulsion or extraction from its mother of an embryo or fetus weighing $500 \mathrm{gm}$ or less when it is not capable of independent survival (WHO). ${ }^{1}$ According to NDHS 2016, Nepal reported the high maternal mortality ratios i.e. 239 deaths per 100,000 live births, attributable to unsafe abortion. Legal, moral and ethical issues surrounding abortion make research on all aspects of abortion difficult to undertake. ${ }^{2,3}$ Abortion is not only a medical problem but also the social problem which poses health risks to women in the reproductive age group. ${ }^{4}$ Abortion was legalized under specified conditions in March 2002 in Nepal but still a large proportion of population is unaware of the abortion.

Thus, the objective of the study is to assess the knowledge and attitude regarding abortion among the women of reproductive age group which will give baseline knowledge for further dissemination and advocacy about various aspects of abortion.

\section{MATERIALS AND METHODS}

A cross-sectional descriptive study was conducted among the women of reproductive age group attending Manipal Teaching Hospital (OBG and Gynae OPD \&Ward), Pokhara, Kaski, Nepal from 13th - 20th March, 2013. Sample size was 100. All the women of reproductive age group (15-45 years) attending MTH were sample population and women who were willing to participate and present at the time of data collection were included in the study. In this study, non-probability purposive sampling technique was used. Interview technique was used for data collection by asking structured questionnaire. Instruments that were used for data collection are Demographic questionnaire, Knowledge questionnaire and Attitude scale. The constructed tool was given to four experts. The experts were requested to judge the items in terms of agree or disagree related to relevance, clarity, accuracy, appropriateness and usefulness to the present study. As per the suggestions and recommendations of the experts, necessary modifications were made in the tool. Tool translation from English to Nepali and Nepali to English was done by a language expert.

The demographic proforma consisted of 6 items. There were 20 multiple choice Knowledge questionnaires. For every right answer score given was 1 and for wrong answer 0 .The scoring was graded as Poor knowledge (1-7), Average knowledge (8-14) and Good knowledge
(15-20) arbitrarily. There were 14 attitude questions and each item was scored on a four point scale from 1 ("strongly disagree") to 4 ("strongly agree") for positive and 4 ("strongly disagree") to 1 ("strongly agree") for negative. The scoring was graded arbitrarily as Unfavorable attitude (1-19), Average positive attitude (20-38) and Good attitude (39-56) arbitrarily. Data was collected from 13th - 20th March, 2013. Ethical Approval was obtained from IRC- Manipal College of Medical Sciences (MCOMS) to conduct research study. Permission was taken from Ethical committee, MTH/MCOMS and Principal, MCOMS (Nursing Programme). Individual consent was taken from the participants after explaining the purpose, objective of the study prior to the data collection. The questionnaire (10\% of the sample size) was pretested among the women of reproductive age group attending MTH (OPD and ward of OBG and Gynae) on 9th March 2013 and they were excluded from the study. Data analysis was done by using descriptive and inferential statistics.

\section{RESULTS}

Data presented in Table 1 show that majority (83\%) of the participants were of age group 15-30 years, $70 \%$ of them were married and most $(82 \%)$ of them were Hindu. Majority (52\%) had nuclear families and $90 \%$ of the participants were literate. Majority of the participants (95\%) had heard something about the term Abortion. Among the participants who had heardregarding abortion, 55\% got information from mass media and the least (2\%) from other sources.

The mean attitude score on abortion among the total participants was $43.39 \pm 4.72$, minimum score was 28 and maximum score was 53. Figure 2 represents that the most $(90 \%)$ of women had good attitude towards abortion and none had poor attitude (fig. 1).

Table 2 shows that there was significant association between knowledge and level of education but no any association was seen with other selected demographic variables.

Table 3 showed that there was asignificant relationship between the knowledge score and attitude score. The attitude level of the women increases with the increase in knowledge level. 
Table 1: Frequency and percentage of demographic variables $(\mathrm{n}=100)$

\begin{tabular}{llll}
\hline \multirow{2}{*}{ Age group } & Characteristics & n & \% \\
Family Type & $15-30$ & 83 & 17 \\
& $31-45$ & 17 & 52 \\
Marital status & Nuclear & 52 & 48 \\
& Joint & 48 & 30 \\
Religion & Unmarried & 30 & 70 \\
& Married & 70 & 82 \\
& Hindu & 82 & 7 \\
Education & Buddhist & 7 & 11 \\
& Christian & 11 & 10 \\
Heard about the term Abortion & Illiterate (who cannot read and write) & 10 & 90 \\
& Literate & 90 & 95 \\
If yes from & Yes & 95 & 5 \\
& No & 5 & 55 \\
& Mass media & 55 & 14 \\
& Family/friends/relatives & 14 & 24
\end{tabular}

Table 2: Association between knowledge score and demographic variables

\begin{tabular}{|c|c|c|c|c|c|}
\hline \multicolumn{6}{|c|}{ Knowledge score } \\
\hline Characteristics & $\begin{array}{l}\text { Poor score } \\
(1-7)\end{array}$ & $\begin{array}{l}\text { Average score } \\
(8-14)\end{array}$ & $\begin{array}{l}\text { Good score } \\
(15-20)\end{array}$ & $\mathrm{x} 2$ & $P$ value \\
\hline Age & & & & 2.84 & 0.303 \\
\hline $15-30 y r s$ & 3 & 51 & 29 & & \\
\hline $31-45 y r s$ & 1 & 7 & 9 & & \\
\hline Marital status & & & & 4.06 & 0.13 \\
\hline Married & 3 & 29 & 38 & & \\
\hline Unmarried & 1 & 19 & 10 & & \\
\hline Type of family & & & & 0.94 & 0.622 \\
\hline Nuclear & 3 & 29 & 20 & & \\
\hline Joint & 1 & 29 & 18 & & \\
\hline $\begin{array}{l}\text { Level of } \\
\text { education }\end{array}$ & & & 21.07 & $0.0001^{*}$ & \\
\hline Illiterate & 3 & 6 & 1 & & \\
\hline Literate & 1 & 52 & 37 & & \\
\hline
\end{tabular}

${ }^{\star}$ Significant at $\mathrm{p}<0.05$ 
Table 3: Correlation between Knowledge Score and Attitude Score

Correlation between Knowledge Score and Attitude Score

Variables r value $\mathrm{p}$ value

Knowledge and 0.47 $0.000^{* *}$

Attitude

${ }^{*}$ significant at $\mathrm{p}<0.05$

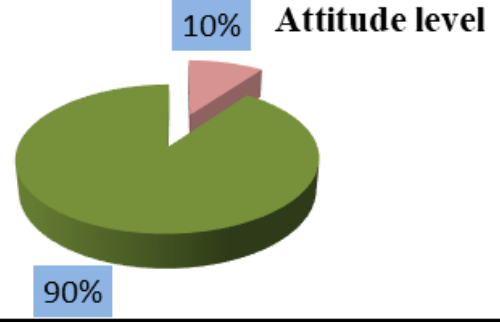

Figure 2: Attitude score

\section{Level of knowledge}

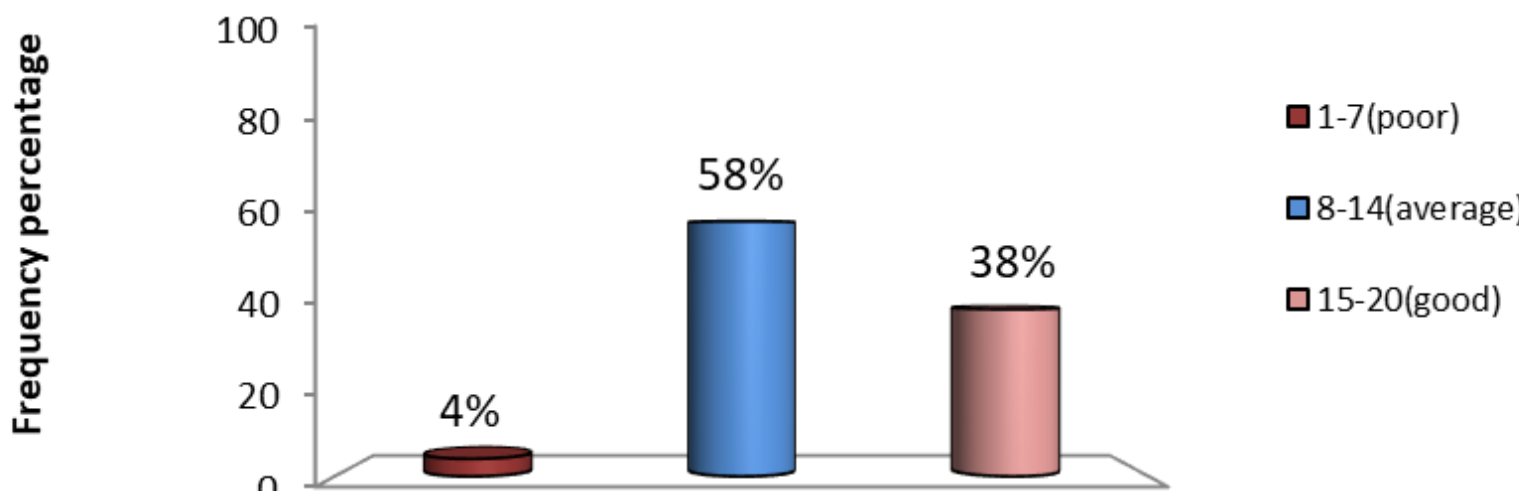

Figure 1: Knowledge Score

\section{DISCUSSION}

A survey carried among women of reproductive age in Nepal during their visit to a Marie Stopes Center in Kathmandu Valley reveled that most were married, had secondary or post-secondary education and the overall knowledge level of abortion among respondents was low to moderate. Respondents' knowledge was associated with their educational attainment ${ }^{6}$ which has almost similar findings with this study conducted in Manipal Teaching Hospital. This may be because who were rich and who had higher level of autonomy are more likely to be aware about the law than their comparison group. ${ }^{7}$

The study which was conducted in Kathmandu revealed $66.5 \%$ women had knowledge on legalization of abortion in Nepal, majority (92.0\%) of the women received information from the media. ${ }^{5}$ So the results support this study as majority had average knowledge regarding the various aspects of abortion including legal issuesand most of the participants got information from mass media. Though majority (55\%) received information from mass media, this is not the satisfied result as expected because most of the information regarding safe motherhood is disseminated through mass media in Nepal. This may be due to the unequal access to information to all the women that affects the level of knowledge. ${ }^{4}$

A descriptive study which was conducted in selected rural areas of Kolar District, Karnata revealed that $63.33 \%$ of women had inadequate knowledge and no women had adequateknowledge regarding abortion. The study findings contradict this study as $38 \%$ had good knowledge regarding various aspects of abortion. Though 38\% had the good knowledge, majority of the women did not had the adequate knowledge regarding various aspects of abortion which may be due to various reasons like unequal access to information, deeplyrooted believes, the prevailing social and cultural structures, low literacyrate, and unsafe abortion and delivery that further increasing the health risk for women.4This study showed that majority (90\%) have good attitude regarding Abortion which is almost similar with the study conducted in Bangkok. The study showed that the sample population had a positive 
attitude towards abortion. ${ }^{9,10}$

National opinion Research Center (NORC) surveyed women on their opinion about abortion. In the case of rape, 86 percent women said abortion was the right choice but the 14 percent said it was not the only choice. ${ }^{9-12}$ The survey supports this study as majority $(72 \%)$ of the women strongly disagreed with the statement "Abortion should not be allowed in case of rape or incest."

Unsafe abortion is a preventable tragedy and is one of the neglected problems of heath care in developing countries. The comprehensive safe abortion educational intervention program is instrumental to improve reproductive age women's knowledge considerably about safe abortion service.

\section{CONCLUSION}

$\mathrm{T}$ hough majority of the women had the good attitude regarding abortion, still few women (4\%) attending MTH didn't have good knowledge. Therefore woman should be educated about abortion which may help to decrease the number of maternal morbidity and mortality due to unsafe abortion. Awareness programmes are suggested regarding various aspects of abortion in Nepal that should cover women of reproductive age group.

Acknowledgement: The authors would like to acknowledge Prof. Naveen Shrestha for his valuable guidance and all respondents who participated in the study.

\section{REFERENCES}

1. Dutta DC. Text book of obstetrics. $7^{\text {th }}$ ed. New central Book Agency Kolkata: India; 2011.

2. Ministry of Health - Nepal, New Era, ICF. Nepal 2016 Demographic and Health Survey Key Findings [Internet]. Kathmandu, Nepal: Ministry of Health Nepal; 2017.

3. Bankole A, Singh S, Haas T. Reasons why women have induced abortions: evidence from 27 countries. International Family Planning Perspectives 1998;24(3): 117-27.https://doi.org/10.2307/3038208 [CrossRef] [GoogleScholar]

4. Acharya A, Bhattarai S. Assessment of the level of knowledge regarding safe abortion among reproductive age group women, a short cross sectional study in lekhnath, kaski. Journal of Institute of Medicine 2017;39(1):105-109. [CrossRef] [GoogleScholar]
5. Tuladhar H, Risal A. Level of awareness about legalization of abortion in Nepal: a study at Nepal Medical College Teaching Hospital. Nepal Med Coll J 2010;12(2):76-80. [GoogleScholar] [PubMed]

6. Khanal P, Sanjel K, Chalise HN. Knowledge and practice of abortion among women in Nepal. AsiaPacific E-Journal of Health Social Science 2014;3(1):16. [GoogleScholar]

7. Adhikari R. Knowledge on legislation of abortion and experience of abortion among female youth in Nepal: a cross sectional study. Reproductive health. 2016; 13: 48. https://doi.org/10.1186/s12978-016-0166-4 [CrossRef] [GoogleScholar] [PubMed]

8. Jabagany J. A study to assess the knowledge and practice of women regarding abortion in selected rural areas of Kolar district, Karnataka. Master [Dissertation]. Karnataka: Rajiv Gandhi University of Health Science; 2005. [GoogleScholar]

9. Bhiromkaew S. The attitudes of people in Bangkok towards abortion. SEAPRAP research report 1982;87. [GoogleScholar]

10. Smith TW, Son J. General social survey 2012 final report: trends in public attitudes towards abortion [report on the Internet]. Chicago, IL: University of Chicago;2013. [GoogleScholar] [Full Text]

11. Chaudhary RK, Jha NK, Manandhar B, Chaudhary K. A study of utilization of abortion service in the tertiary hospital of western region of Nepal. Journal of Karnali Academy of Health Sciences 2019;2(1):27-33.https:// doi.org/10.3126/jkahs.v2i1.24411 [CrossRef]

12. Shrestha A, Sharma S. Status of abortion services in Jumla. Journal of Karnali Academy of Health Sciences 2018;1(2):47-49.https://doi.org/10.3126/jkahs. v1i2.24138 [GoogleScholar] 